\title{
Tinjauan Hukum Islam terhadap Biaya Pemungutan Sewa Lapak Pasar Tradisional X
}

\section{Dea Paramita Adriani*}

Prodi Hukum Ekonomi Syariah, Fakultas Syariah, Universitas Islam Bandung, Indonesia.

\author{
*Dheaadriani25@gmail.com
}

\begin{abstract}
One of the activities in muamalah is a rental transaction. Regarding the lease transaction, it is a transaction that has often been carried out by the public in general, especially in the economic field. Leasing in Islamic law is called Al-Ijarah. In carrying out the Ijarah contract, there must be agreement and justice between the two parties. However, in practice there are still many who ignore fairness in transactions. As is the case, the difference in the price of lapak rentals that occurs in the Limbanang traditional market, where market officials quote market stall rental fees to tenants from outside the Limbanang village is higher than that of tenants from Nagari Limbanang itself. Therefore, this study aims to find out the review of Islamic law regarding the cost of collecting rental fees for the traditional market stalls of Limbanang. The type of data used is field research with a sociological juridical approach used to collect data in this study. In addition, data collection techniques in the form of interviews observasions, and documentation were carried out the strengthen the research data. Meanwhile, data reduction, data presentation, and conclusion drawing where used to analyze the data in this study. The results of this study conclude that the difference in rental prices applied by market managers based on where the tenants live is less common because it contains elements of tyranny and injustice.
\end{abstract}

Keywords: Islamic Law, Muamalah, Leasing (Al-Ijarah).

Abstrak. Salah satu aktivitas pada bermuamalah ialahh transaksi sewaa menyewab. Perihal transaksi sewa menyewa adalah transaksi yang sudah sering dilakukan oleh masyarakat pada umumnya, terutama dalam bidang ekonomi. Sewa menyewa dalam hukum Islam disebut dengan Al-Ijarah. Dalam melaksanakan akad Ijarah harus adanya kesepakatan dan keadilan di antara kedua belah pihak. Namun, pada praktiknya masih banyak yang mengabaikan keadilan dalam bertransaksi. Seperti halnya, perbedaann harga sewa lapaks yang terjadi di pasar tradisional Limbanang, dimana petugas pasar mengutip biaya sewa lapak pasar kepada penyewa yang berasal dari luar nagari Limbanang lebih tinggi dibandingkan dengan penyewa yang berasal dari Nagari limbanang itu sendiri. Oleh karena itu, penelitian ini bertujuan untuk mengetahui praktik penetapan harga sewa lapak pasar tradisional Limbanang dan untuk mengetahui tinjauan hukum Islam terhadap biaya pemungutan sewa lapak pasar tradisional Limbanang. Jenis data yang digunakan adalah penelitian lapangan dengan pendekatan yuridis sosiologis yang digunakan untuk mengumpulkan data pada penelitian ini. Selain itu, teknik pengumpulan data berupa wawancara, observasi, dan dokumentasi dilakukan untuk memperkuat data penelitian. Sedangkan reduksi data, penyajian data, dan penarikan kesimpulan digunakan untuk menganalisa data pada penelitian ini. Hasil penelitian ini menyimpulkan bahwa perbedaan harga sewa yang diterapkan oleh pengelola pasar berdasarkan tempat tinggal para penyewa kurang lazim untuk dilakukan karena mengandung unsur kedzaliman dan ketidakadilan.

Kata Kunci: Hukum Islam, Muamalah, Sewa Menyewa (Al-Ijarah). 


\section{A. Pendahuluan}

Manusia biasa dipandang sebagai homoeconomicus, yang berarti menjadi makhluk yangs berorientasi pada ekonomi serta bertindak rasional. Manusia ialah makhluk yang tak bisa hidup sendiri tanpa adanya bantuan dari manusia yang lain.

Salah satu aktivitas transaksi ekonomi yaitu sewa menyewa. Tentang transaksi sewa menyewa ialah transaksi yang telah lazim dilakukan oleh masyarakat pada umumnya, karena kebutuhan manusia semakin tinggi. Pada Islam aktivitas sewa menyewa sering disebut dengan akad Ijarah.

Ijarah berarti menyampaikan manfaat sesuatu pada orang lain dengan adanya ganti pembayaran. Jadi sewa menyewa berarti akad pemindahan hak guna atas suatu barang ataupun jasa di waktu tertentu diikuti dengan upah/gaji tanpa diikuti pemindahan kepemilikan barang itu sendiri.

Transaksi sewa menyewa diatur dalam alquran dan hadist untuk dijadikan landasan bagi setiap kegiatan yang dilakukan. Salah satu aturan hukum yang terkait masalah sewa (ijarah) terdapat juga dalam Al quran dan Hadist, disebutkan dalam al-Quran surat Al Zukhruf (43) ayat 32:

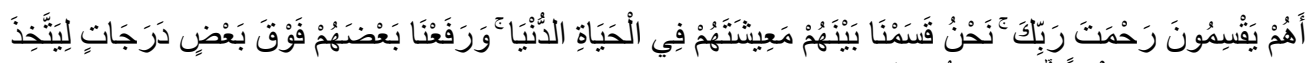

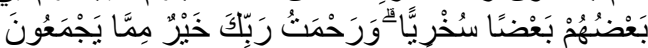

"Apakah mereka yang membagi-bagi rahmat Tuhanmu? Kami telah menentukan antara mereka penghidupan mereka dalam kehidupan dunia, dan kami telah meninggikan sebahagian mereka atas sebahagian yang lain beberapa derajat, agar sebagian mereka dapat mempergunakan sebagian yang lain. Dan rahmat Tuhanmu lebih baik dari apa yang mereka kumpulkan."

(Qs.Az-Zukhruf :32)

Jika ditinjau dari hukum Islam, pada dasarnya seorang muslim berhak diperlakukan sama dan adil terutama dalam hubungan bermuamalah. Khususnya mengenai penetapan harga sewa lapak pasar tradisional Limbanang. Karena urusan muamalah sudah ditegaskan oleh Allah Swt dalam kaidah:

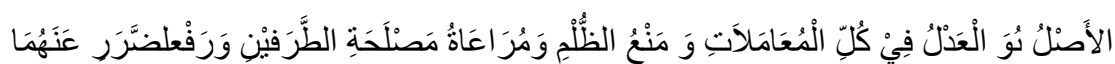

"Asal setiap muamalah adalah adil dan larangan berbuat zalim serta memperhatikan kemaslahatan kedua belah pihak dan menghilangkan kemudharatan"

Pasar Tradisional Limbanang, Kecamatan Suliki, Kabupaten Lima Puluh Kota, Sumatera Barat adalah pasar yang beroperasi setiap hari Kamis dari pagi sampai sore setiap minggunya. Pedagang yang berjualan di pasar tersebut sebagian berasal dari desa itu sendiri dan sebagian berasal dari penduduk luar desa tersebut.

Sewa lapak di pasar Tradisional ini dibayarkan kepada pihak pengelola pasar yang mengutip uang sewa ketika pihak yang melakukan pengutipan meminta uang sewa lapak pasar kepada para pedagang di lapak masing-masing sesuai dengan jenis lapak yang disewa oleh para pedagang, namun pada prakteknya petugas pasar mengutip harga sewa lapak sesuai dengan domisili para penyewa lapak.

Perbedaan biaya sewa lapak yang terjadi di pasar Tradisional Limbanang yang dikutip sesuai tempat tinggal para penyewa. Domisili para penyewa lapak pasar mengakibatkan adanya perbedaan harga sewa lapak antara penduduk asli desa Limbanang dan penduduk yang berasal dari luar desa Limbanang yang mengakibatkan adanya unsur ketidakadilan diantara para penyewa lapak.

Pedagang yang berasal dari luar desa Limbanang merasa dirugikan dan merasa tidak adanya keadilan dalam sistem pembayaran harga sewa lapak pasar tradisional Limbanang, Kecamatan Suliki, Kabupaten Lima Puluh Kota, Sumatera Barat ini yang berimplikasi adanya mukhalafat asy-syuruth yang berarti menyalahi isi dan substansi yang disepakati dalam akad yang menyebabkan adanya gharar dalam ujrah (sewa menyewa) lapak pasar di Desa Limbanang, Kecamatan Suliki, Kabupaten Lima Puluh Kota, Sumatera Barat.

Dari kegiatan dan mekanisme sewa menyewa lapak pasar tradisional Limbanang tersebut, maka penulis ingin mengetahui dan meninjau atau menganalisis lebih dalam lagi bagaimana sistem pemungutan biaya sewa lapak pasar dari segi hukum Islam yang akan dituangkan dalam sebuah skripsi yang berjudul "Tinjauan Hukum Islam terhadap Biaya 
Pemungutan Sewa Lapak Pasar Tradisional Limbanang (Studi Kasus di Nagari Limbanang Kecamatan Suliki Kabupaten Lima Puluh Kota, Sumatra Barat)".

Sesuai latar belakang yang sudah diuraikan di atas maka rumusan masalah pada penelitian ini sebagai berikut: Bagaimana praktik penetapan harga sewa lapak pasar tradisional Limbanang, Kecamatan Suliki, Kabupaten 50 Puluh Kota, Sumatra Barat? bagaimana tinjauan hukum Islam tentang biaya pemungutan sewa lapak pasar tradisional Limbanang, Kecamatan Suliki, Kabupaten 50 Puluh Kota, Sumatra Barat? Selanjutnya tujuan dari penelitian ini adalah:

1. Guna mengetahui praktik penetapan harga sewa lapak pasar tradisional Limbanang, Kecamatan Suliki, Kabupaten Lima 50 Kota, Sumatra Barat.

2. Guna mengetahui tinjauan hukum Islam terhadap biaya pemungutan sewa lapak pasar tradisional Limbanang, Kecamatan Suliki, Kabupaten 50 Puluh Kota, Sumatra Barat.

\section{B. Metodologi Penelitian}

Peneliti menggunakan metode pendekatan yuridis sosiologis yaitu menekankan penelitian yang bertujuan untuk memperoleh pengetahuan hukum yaitu terjun langsung ke objeknya dengan maksud dan tujuan untuk menemukan fakta (fact funding). Penelitian ini berjenis penelitian lapangan (field research). Data dalam penelitian ini bersumber dari dari data primer dan data sekunder. Teknik pengumpulan data yang digunakan dalam penelitian ini adalah wawancara, observasi, dan dokumentasi. Teknik analisis data yang digunakan yaitu teknik analisis data deskriptif kualitatif.

\section{Hasil Penelitian dan Pembahasan}

Praktik Penetapan Harga Sewa Lapak Pasar Tradisional Limbanang, Kecamatan Suliki, Kabupaten Lima Puluh Kota, Sumatra Barat.

Dalam kehidupan sehari-hari masyarakat sering dihadapkan dengan kegiatan jual belii atau tukar menukar barang atau sering disebut dengan perniagaan. Perniagaan atau perdagangan ialah aktivitas tukart menukart barang ataupun jasa atas kesepakatan bersama tanpa adanya unsur pemaksaan dari pihak manapun. Pasar ialah tempat bertemunya penjual dan pembeli dalam melakukan transaksi.

Pasar Limbanang terdiri dari kios, los, dan lapak. Lapak adalah tempat atau pelataran yang berada di luar kios dan luar los. Lapak- lapak yang ada di Pasar Limbanang disewa atau ditempati oleh para pedagang yang berasal dari luar desa Limbanang dan penduduk desa Limbanang.

Lapak merupakan prasarana penting bagi para pedagang yang menyewa di pasar Limbanang. Karena lapak merupakan tempat milik penyewa/pedagang untuk berjualan di pasar Limbanang yang tidak bisa diganggu oleh penyewa lainnya termasuk penduduk desa Limbanang.

Pasar limbanang dibagi menjadi 3 bagian, bagian pertama yaitu bagian depan yang merupakan tempat kebutuhan untuk sandang, pangan, dan papan. Artinya di bagian depan merupakan tempat kebutuhan pokok sehari-hari bagi masyarakat yang terdiri dari pakaian, makanan dan alat alat kebutuhan rumah tangga.

Sedangkan untuk bagian kedua yaitu bagian tengah yang terdiri dari pedagang sayuran dan makanan pokok. Di bagian tengah ini banyak ditemukannya pedagang-pedagang sayuran yang berasal dari Nagari Limbanang maupun di luar Nagari Limbanang`

Dan untuk bagian ketiga yaitu bagian belakang merupakan tempat untuk para pedagang ikan dan daging. Jika pembeli ingin membeli daging dan juga ikan, maka pembeli dapat menjumpainya di bagian belakang di Pasar Limbanang.

Ketiga bagian pasar yang sudah dipapaparkan di atas sudah ditentukan oleh pengelola pasar Limbanang dan para pedagang yang berjualan atau mempunyai lapak di Pasar Limbanang wajib mengikuti aturan yang telah dibuat oleh pengelola pasar Limbanang baik berupa tempat maupun harga lapak yang telah disewakan.

Praktik penetapan harga sewa lapak pasar tradisional Limbanang yaitu dipatok berdasarkan besar kecilnya tempat yang disewakan kepada para pedagang. Harga sewa lapak yang ditetapkan oleh pengelola pasar Tradisional Limbanang yaitu untuk Kios Rp. 10.000 per 
minggu, untuk los Rp. 8.000 per minggu dan untuk lapak Rp. 5.000 per minggu nya. Pengutipan harga sewa lapak dilakukan oleh petugas pasar yang mana pengutipan harga sewa lapak pasar dilakukan tiap minggu yaitu pada hari Kamis saat pasar beroperasi.

Akan tetapi pada praktiknya petugas pasar mengutip biaya sewa kepada para pedagang tidak sesuai dengan kesepakatan yang telah dibuat di awal perjanjian. Mereka mengutip harga sewa lapak di atas harga yang sudah ditetapkan. Alasannya karena para pedagang banyak yang berasal dari luar Nagari Limbanang. Para pedagang merasa kecewa atas perlakuan dari petugas yang mengutip biaya sewa.

Tinjauan Hukum Islam terhadap Biaya Pemungutan Sewa Lapak Pasar Tradisional Limbanang, Kecamatan Suliki, Kabupaten Lima Puluh Kota, Sumatra Barat.

Sewa menyewa dalam aturn hukum Islam biasa disebut dengan Akad Ijarah. Secara bahasa, alijarah berasal dari kata al-ajru, yang artinya ialah ganti atau upah.

Kamus al-Munawwir juga menjelaskan bahwa, kata ijarah direvasikan dari bentuk fi'il "ajara-ya'juru-ajran". Ajran sendiri memiliki makna yang sama dengan kata al-iwadh yang artinya ganti dan upah.

Sedangkan menurut istilah dalam Kamus Besar Bahasa Indonesia (KBBI), sewa menyewa (Ijarah) berarti pemakaian sesuatu dengan pembayaran uang.

Perihal perbedaan harga sewa menyewa intinya dalam hukum Islam tak diterangkan secara rinci, tidak terdapat dalil alquran dan hadist yang mengatur tentang perbedaan harga dalam sewa menyewa. Pada dasarnya setiap aktivitas muamalah itu diperbolehkan selama belum ada dalil yang melarangnya. Hal ini sesuai dengan kaidah fiqih yang berbunyi:

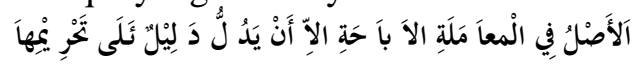

Artinya: "Hukum asal sesuatu adalah boleh, hingga ada dalil yang menunjukkan keharamannya

Kaidah di atas bermaksud setiap transaksi apapun itu boleh dilakukan, seperti halnya jual beli, sewa menyewa, kerja sama, gadai, perwakilan, dan lain sebagainya. Kecuali yang haram untuk dilakukan seperti tipuan, gharar, perjudian serta riba.

Maksud kaidah di atas ialah bahwa pada setiap muamalah dan transaksi intinya boleh dilakukan, seperti jual beli, sewa menyewa, gadai, kerja sama (mudharabah atau musyarakah), perwakilan (wakalah), dan lain lain, kecuali yang tegas diharamkan seperti mengakibatkan kemudaratan seperti tipuan (tadlis), ketidakpastian (tahgrir), perjudian dan riba.

Pada dasarnya seluruh akad transaksi dalam islam harus adil dan transparan, demikianlah yang diajarkan dalam hukum islam. Berdasarkan kaidah fiqih di atas, hukum perbedaan harga sewa menyewa dalam islam adalah mubah (boleh), sebab belum ada dalil yang melarangnya.

Salah satu dasar hukum akad ijarah terdapat dalam Q.S Az-zukhruf: 32 yang berbunyi:

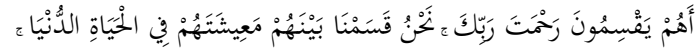

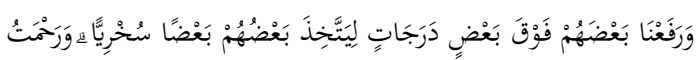

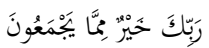

"Apakah mereka yang membagi-bagi rahmat Tuhanmu? Kami telah menentukan antara mereka penghidupan mereka dalam kehidupan dunia, dan kami telah meninggikan sebahagian mereka atas sebahagian yang lain beberapa derajat, agar sebahagian mereka dapat mempergunakan sebagian yang lain. Dan rahmat Tuhanmu lebih baik dari apa yang mereka kumpulkan."

Ayat di atas menjelaskan tentang kebolehan dalam sewa menyewa. Tafsir ayat di atas menjelaskan bahwa allah telah melebihkan sebagian hamba di atas sebagian yang lainnya di dunia, yaitu agar sebagian yang lain itu dapat dimanfaatkan oleh sebagian yang lain salah satunya yaitu dengan memanfaatkan jasanya dan mendapat upah atas pekerjaannya tersebut.

Dalam konsep upah mengupah bila barang yang disewakan pada penyewa rusak sebab kelalaiannya, maka pihak penyewa berkewajiban untuk mengganti kerugian tersebut dan kebalikannya bila barang yang disewakan itu rusak bukan karena kelalaiannya, maka penyewa tidak berkewajiban untuk menggantinya. Hal ini sesuai dengan kaidah fiqih: 
الأَجْرُ وَالضَّمَمَانُ لاَ يَجَتَمِعَانِ

Artinya: "Upah (membayar uang sewaan) dan tanggungan (ganti rugi) tidak berkumpul.

Kaidah tersebut maksudnya berkaitan dengan tidak ada keharusan membayar upah dalam keadaan diharuskan adanya tanggungan (daman). Daman disini maksudnya adalah ganti rugi dengan cara mengganti barang yang serupa apabila masih terdapat di pasaran. Namun, apabila tidak ada barangnya di pasaran, maka ganti ruginya dengan cara membayar seharga barang tersebut.

Ijma ulama memperbolehkan dhaman dalam muamalah, karena dhaman (tanggungan) dalam muamalah diperlukan dalam waktu-waktu tertentu, seperti halnya sewa menyewa. Jika terjadi kerusakan terhadap barang yang disewa, maka si penyewa berhak menanggung kerusakan tersebut jika itu terjadi karena kelalaiannya, dan sebaliknya, jika kerusakan itu terjadi bukan karena kelalaian si penyewa, maka si penyewa tidak berhak mengganti kerugian yang terjadi terhadap objek sewa.

Allah 'Azza wa Jalla berfirman dalam QS Al-Maidah ayat 8 yang berbunyi:

$$
\text { تَعْمَلُونَ }
$$

"Hai orang-orang yang beriman hendaklah kamu jadi orang-orang yang selalu menegakkan (kebenaran) karena Allah, menjadi saksi dengan adil. Dan janganlah sekali-kali kebencianmu terhadap sesuatu kaum, mendorong kamu untuk berlaku tidak adil. Berlaku adillah, karena adil itu lebih dekat kepada takwa. Dan bertakwalah kepada Allah, sesungguhnya Allah Maha mengetahui apa yang kamu kerjakan."

Hal ini karena kezaliman adalah sumber kerusakan dan keadilan adalah sumber kesuksesan yang menjadi tonggak kemaslahatan hamba di dunia dan di akhirat, sehingga manusia sangat membutuhkannya dalam segala kondisi. Ketika perniagaan dan muamalah adalah pintu yang besar bagi kezaliman manusia dan pintu untuk memakan harta orang lain dengan bathil, maka larangan zalim dan pengharamannya termasuk maqshid syariah terpenting dalam muamalah kewajiban berbuat adil dan larangan berbuat zalim menjadi kaidah terpenting dalam muamalah.

Pada kehidupan sehari-hari masyarakat sering dihadapkan dengan aktivitas jual beli atau tukar menukar barang atau seringkali disebut dengan perniagaan. Perniagaan atau perdagangan ialah aktivitas tukar menukar barang ataupun jasa tanpa adanya paksaan dari pihak manapun. Pasar artinya tempat bertemunya penjual dan pembeli dalam melakukan transaksi.

Perbedaan harga sewa lapak yang terjadi di Pasar tradisional Limbanang merupakan kebijakan yang sudah diatur oleh pengelola pasar. Tetapi perbedaan harga yang diterapkan oleh pengelola pasar berdasarkan tempat tinggal para penyewa kurang lazim untuk dilakukan, karena penyewa yang berasal dari luar Nagari Limbanang merasa dirugikan atas kebijakan tersebut

Pada saat melakukan kesepatan di awal perjanjian antara pihak pengelola pasar dengan penyewa yang berasal dari luar nagari Limbanang, pengelola pasar mengatakan bahwa harga sewa untuk penyewa yang berasal dari luar nagari Limbanang tarifnya sama dengan penyewa yang berasal dari penduduk asli Nagari Limbanang. Tetapi pada praktiknya, tarif sewa lapak yang dipungut berbeda dengan penyewa yang berasal dari penduduk asli Nagari Limbanang.

Perbedaan harga sewa lapak yang terjadi di Pasar tradisional Limbanang mengandung unsur kedzaliman dan ketidakadilan, yang menyebabkan penyewa yang berasal dari luar penduduk Nagari limbanang merasa dirugikan dan tidak disamakan dengan penyewa yang berasal dari Nagari itu sendiri.

\section{Kesimpulan}

Berdasarkan uraian sebagaimana yang telah penulis kemukakan dalam poin-poin sebelumnya, maka dapat diambil kesimpulan bahwa:

1. Perjanjian yang dilakukan oleh pengelola pasar dengan para penyewa lapak pasar radisional Limbanang dilakukann secara lisan. Namun pada pelaksanaannya petugas pasar mengutip biaya sewa lapak pasar berdasarkan domisili atau tempat tinggal para penyewa yang mana harga biaya sewa lapak berbeda antara penyewa yang berasal dari 
nagari Limbanang dan yang berasal dari luar Nagari Limbanang.

2. Tentang perbedaan harga sewa menyewa dalam hukum Islam tidak diterangkan secara rinci, tidak ada dalil alquran dan hadist yang mengatur tentang perbedaan harga di dalam sewa menyewa. Perbedaan harga sewa lapak merupakan kebijakan yangh sudah diatur oleh pengelola pasar. Perbedaan harga sewa yang dilakukan oleh petugas pasar mengandung unsur kedzaliman dan ketidakadilan, karena penyewa yang berasal dari luar nagari Limbanang merasa dirugikan atas tindakan tersebut. Ditinjau dari hukum Islam, menurut ulama fiqih hal ini bertentangan dengan hukum islam karena mengandung unsur ketidakadilan.

\section{Acknowledge}

Dalam proses penyusunan skripsi ini, penulis mendapat bantuan dari berbagai pihak. Oleh karena itu dalam kesempatan ini penulis ingin mengucapkan terima kasih kepada, Allah SWT yang telah melimpahkan rahmat dan karunia-Nya kepada penulis, sehingga penulis diberi kelancaran dan kemudahan dalam menyelesaikan skripsi ini. Ayahanda Yandi Adrian serta Ibunda Rita Adrianti tercinta yang selalu memberi doa, motivasi, semangat, kasih sayang yang tak pernah putus bagi penulis, semoga Allah SWT dapat memuliakannya. Saudara kandung tercinta Dheva Agustin Adriyan, Adhitya Muhammad Putra, Diana Shakilla Adrian yang selalu mendukung, memotivasi dan mendoakan penulis. Ibu Titin Suprihatin, Dra., M. Hum selaku Dekan Fakultas Syari'ah Universitas Islam Bandung. Bapak Arif Rijal Anshori, S.Sy., M.E selaku Ketua Jurusan Program Studi Hukum Ekonomi Syari'ah Fakultas Syari'ah Universitas Islam Bandung. Bapak Panji Adam Agus Putra, S.Sy., M.H selaku Dosen Pembimbing I yang telah membimbing penulis dengan sangat sabar dan ikhlas dalam menyelesaikan skripsi ini. Bapak Redi Hadiyanto, S.Sy., M.H selaku Dosen Pembimbing II yang telah membimbing penulis dengan sangat sabar dan ikhlas dalam menyelesaikan skripsi ini. Segenap Dosen dan seluruh Staff Tata Usaha Fakultas Syari'ah Universitas Islam Bandung. Kepada Petugas pasar dan Pengelola pasar tradisional Limbanang yang telah memberikan izin kepada penulis untuk melakukan penelitian. Sahabat sejak awal perkuliahan, Destriana Andani, Maharani Salma, terima kasih selalu membantu dalam segala hal serta selalu memberi dukungan dan motivasi dalam perkuliahan hingga penyusunan skripsi ini. Teman dekat saya Harya Amnesty Arsyad yang selalu memberikan dukungan dan motivasi kepada penulis dalam penyelesaian skripsi ini. Sahabat-sahabat seperjuangan Fakultas Syari'ah Angkatan 2017, terutama kelas A yang telah memberikan bantuan serta dukungan kepada penulis. Semua pihak yang telah memberikan bantuan kepada penulis dalam menyelesaikan skripsi ini

\section{Daftar Pustaka}

[1] Kotler P. Manajemen Pemasaran [Internet]. Jakarta: Indeks; 2005. Available from: 1. Yusnadi dkk, Filsafat Pendidikan (Medan: HalamanMoeka, 2019) Hal 3,11

[2] Muhammad bin Abu Bakar As-Sarakhsi, Al-Mabsut Al Fiqh 'ala Al-Mazhab Al-Arba'ah Silsilah Al-'Ilm An-Nafi', (Al-Isdhar Al-Awwal, 1426 H), Juz. 6, Seri.9, h.319

[3] Ali Fikri, Al Mu'amalat Al-Maddiyah wa Al-Adabiyyah, (Mesir: Mushthafa Al-Babiy AlHalaby, 1358 H), cet. I, h. 85

[4] Panji Adam, S.Sy., M.H, Fiqih Muamalah Maliyah: Konsep, Regulasi, dan Implementasi (Bandung:PT Refika Aditama, 2017) Hal. 197-198

[5] Enang Hidayat, M. Ag, Kaidah Fikih Muamalah, Bandung: PT Remaja Rordakarya, 2019, Hlm.84

[6] Haroen Nasroen. (2000). Fiqih Muamalah. Gaya Media Pratama.

[7] https://yufidia.com/2629-kaidah-asal-setiap-muamalah-adalah-adil-dan-larangan-berbuatzalim.html

[8] Qs. Az-Zhukrhuf : 32

[9] A. W. al-Munawwir, Kamus al-Munawwir, Surabaya: Pustaka Progresif, 1997, Hal. 9 
[10] Pusat Bahasa Departemen Pendidikan Nasional, Kamus Besar Bahasa Indonesia, Jakarta: Balai Pustaka, 2005, Edisi-3, Hal. 1057

[11] Departemen Agama RI, Al-Qur'an Tajwid dan Terjemah (Bandung, Diponegoro, 2010) Hal. 70

[12] Ashur, Ahmad isa, Al-Fiqh Al Muyassar Fi Al-Muamalat, Tangerang: Dar Al-aqsha, 6/123

[13] Departemen Agama RI, Alqur'an dan terjemahannya, Hal. 106 